\title{
Measuring the response of macroeconomic uncertainty to shocks
}

Article

Accepted Version

Shields, K., Olekalns, N., Henry, Ó. T. and Brooks, C. (2005) Measuring the response of macroeconomic uncertainty to shocks. Review of Economics and Statistics, 87 (2). pp. 362370. ISSN 1530-9142 doi: https://doi.org/10.1162/0034653053970276 Available at https://centaur.reading.ac.uk/20556/

It is advisable to refer to the publisher's version if you intend to cite from the work. See Guidance on citing.

Published version at: http://www.mitpressjournals.org/toc/rest/87/2

To link to this article DOI: http://dx.doi.org/10.1162/0034653053970276

Publisher: MIT Press

All outputs in CentAUR are protected by Intellectual Property Rights law, including copyright law. Copyright and IPR is retained by the creators or other copyright holders. Terms and conditions for use of this material are defined in the End User Agreement.

\section{www.reading.ac.uk/centaur}

\section{CentAUR}

Central Archive at the University of Reading 
Reading's research outputs online 


\title{
MEASURING THE RESPONSE OF MACROECONOMIC UNCERTAINTY TO SHOCKS
}

\author{
Kalvinder Shields, Nilss Olekalns, Ólan T. Henry, and Chris Brooks*
}

\begin{abstract}
Recent research documents the importance of uncertainty in determining macroeconomic outcomes, but little is known about the transmission of uncertainty across such outcomes. This paper examines the response of uncertainty about inflation and output growth to shocks documenting statistically significant size and sign bias and spillover effects. Uncertainty about inflation is a determinant of output uncertainty, whereas higher growth volatility tends to raise inflation volatility. Both inflation and growth volatility respond asymmetrically to positive and negative shocks. Negative growth and inflation shocks lead to higher and more persistent uncertainty than shocks of equal magnitude but opposite sign.
\end{abstract}

\section{Introduction}

$\mathrm{T}$ HE role of uncertainty is central in many macroeconomic models explaining the dynamics of economic activity and inflation. Friedman (1977), for example, argued that uncertainty adversely affects the ability of the price mechanism to allocate resources efficiently; in Friedman's analysis, uncertainty regarding the realization of inflation is a contributing factor in slowing the rate of economic growth. ${ }^{1}$ More recently, Huizinga (1993) argued that a greater degree of inflation uncertainty implies that actual realizations of inflation have a larger unexpected component, and could therefore have larger real effects. Hayford (2000) argued that high inflation will produce high inflation uncertainty in a world in which there is confusion regarding the monetary authority's predisposition toward lowering inflation. He identified a spillover between uncertainty about inflation and real economic activity and shows that this can affect real output growth. Uncertainty also features in some models of the monetary policy transmission mechanism. Cukierman and Meltzer (1986) showed that a monetary authority wishing to enact an expansionary policy can exploit inflation uncertainty; in effect, the authority can use the uncertainty to cloak a high-inflation policy in an attempt to boost economic activity. Links between growth uncertainty and real activity have also been hypothesized. Black (1987) suggested there will be a positive relation because in times of growth uncertainty the riskiest investment projects become more profitable. Woodford (1990), however, hypothesized a negative relation based on the increased riskiness of investment when output is volatile. ${ }^{2}$

Received for publication January 9, 2003. Revision accepted for publication July 28, 2004

* The University of Melbourne (K.S., N.O., and Ó.T.H.) and ISMA Centre, The University of Redding (C.B.).

The usual disclaimer applies to any errors or omissions.

${ }^{1}$ See also Okun (1971).

${ }^{2}$ The empirical literature relating macroeconomic performance to growth and inflation uncertainty has produced mixed results. Numerous papers have tested for a link between output uncertainty and growth (Ramey \& Ramey, 1995; Kormendi \& Meguire, 1985; Grier \& Tullock, 1989; Caporale \& McKiernan, 1996; Grier \& Perry, 2000; and Henry \& Olekalns, 2002, inter alia). The results span the complete range from a
In the empirical literature, researchers have generally adopted one of three approaches when modeling macroeconomic uncertainty. The first approach uses the unconditional second moments of the data. Examples include Logue and Willet (1976), Taylor (1981), and Ramey and Ramey (1995) inter alia. Other papers use the dispersion of survey forecasts of inflation and real activity to proxy uncertainty (Cukierman \& Wachtel, 1979; Hayford, 2000, inter alia). Finally, increasing use has been made of time series models of conditional heteroskedasticity (Engle, 1982, 1983; Jansen, 1989; and Henry and Olekalns 2002, inter alia).

In this paper, we provide a new empirical characterization of macroeconomic uncertainty by jointly modeling the conditional variance-covariance process underlying real economic activity and inflation. ${ }^{3}$ Our approach improves on much of the previous research in allowing for the possibility of a different dynamic response of uncertainty to positiveand negative-signed macroeconomic shocks and uncertainty spillovers across macroeconomic outcomes. Moreover, we make use of a new analytical tool, the variance impulse response function (VIRF); in our analysis, VIRFs (i) allow quantification of the extent to which uncertainties about real activity and inflation are interrelated, (ii) characterize the magnitude and persistence of macroeconomic uncertainty following a shock, and (iii) provide evidence of significantly different responses of macroeconomic uncertainty to shocks, depending on the sign of these shocks. Unlike constant-correlation models, commonly used in multivariate analysis, our approach has the advantage of not requiring the conditional correlation coefficient between real activity and inflation to be time-invariant. ${ }^{4}$

Our paper proceeds as follows. Section II describes the data; section III outlines the statistical model. Estimates and diagnostic tests are presented in section IV. Section V describes the VIRFs, and finally, section VI presents some concluding comments.

negative to a zero to a positive relation. There is an equally large literature that relates inflation uncertainty and real output [see Holland (1993) for a survey]. Here, there is a predominance of papers that find a negative relation [see Grier et al. (2004) for a recent study].

${ }^{3}$ Our focus is on the conditional second moments of the data. This is appropriate for our purpose because one of our primary aims is to document the persistence of shocks to the variance-covariance process of inflation and real activity. This would not be possible if we worked with the unconditional second moments. Nor is there likely to be sufficient variation over time in survey-based measures of uncertainty to enable identification of the effects of shocks to the variance-covariance process.

${ }^{4}$ An example of a constant-correlation approach to the joint modeling of real activity and inflation is the paper by Grier and Perry (2000). 
TABLE 1.-SUMMARY STATISTICS

\begin{tabular}{|c|c|c|c|c|c|}
\hline Variable & Mean & Variance & Skewness & Excess Kurtosis & Bera-Jarque Normality \\
\hline$y$ & 3.6054 & 155.7047 & 0.2428 & 4.5962 & $\begin{array}{c}562.4889 \\
{[0.0000]}\end{array}$ \\
\hline$\pi$ & 3.0559 & 37.5103 & 1.1579 & 4.4310 & $\begin{array}{c}658.2563 \\
{[0.0000]}\end{array}$ \\
\hline
\end{tabular}

\begin{tabular}{|c|c|c|c|c|c|}
\hline \multicolumn{6}{|c|}{ Unit Root and Stationarity Tests } \\
\hline Variable & $\operatorname{ADF}(\tau)$ & $\operatorname{ADF}(\mu)$ & $\mathrm{ADF}$ & $\operatorname{KPSS}(\mu)$ & $\operatorname{KPSS}(\tau)$ \\
\hline$y$ & -12.4483 & -12.4438 & -11.6179 & 0.07595 & 0.03498 \\
\hline$\pi$ & -5.4309 & -5.3842 & -4.3728 & 0.4664 & 0.3975 \\
\hline $5 \%$ C.V. & -3.4191 & -2.8664 & -1.9399 & 0.463 & 0.146 \\
\hline
\end{tabular}

Tests for Serial Correlation and $\mathrm{ARCH}$

\begin{tabular}{cccc} 
Variable & $Q(4)$ & $Q(12)$ & ARCH(4) \\
\hline$y$ & 165.3173 & 192.0829 & 52.1685 \\
& {$[0.0000]$} & {$[0.0000]$} & $68.0000]$ \\
& 321.3849 & {$[0.0000]$} & 62.7177
\end{tabular}

Tests for Size and Sign Bias in Variance

\begin{tabular}{cccc} 
Variable & Sign & Neg. Size & Pos. Size \\
\hline$y$ & 0.2418 & -7.19740 & 3.2857 \\
\multirow{2}{*}{$\pi$} & {$[0.0159]$} & {$[0.0000]$} & {$[0.0011]$} \\
& -0.9672 & 0.5698 .3489 & 8.6105 \\
{$[0.3338]$} & {$[0.5690]$} & 72.2217 & {$[0.0000]$} \\
\hline
\end{tabular}

Note: $P$-values displayed as $[\cdot]$. The $\mathrm{ARCH}(4)$ tests and the tests for size and sign bias are based on residuals from a fourth-order autoregression

\section{Data Description}

The data used in this study were obtained from the FRED database at the Federal Reserve Bank of Saint Louis. The sample comprises monthly data over the period April 1947 to October 2000. We measure inflation, $\pi_{t}$, as the annualized monthly difference of the logarithm of $P_{t}$, the producer price index:

$$
\pi_{t}=\log \left(\frac{P_{t}}{P_{t-1}}\right) \times 1,200
$$

Similarly, we measure real activity, $y_{t}$, as the annualized monthly difference of the logarithm of $I_{t}$, the index of industrial production:

$$
y_{t}=\log \left(\frac{I_{t}}{I_{t-1}}\right) \times 1,200 .
$$

Table 1 presents summary statistics for the data. Both real activity and inflation are positively skewed and display significant amounts of excess kurtosis, both series failing to satisfy the null hypothesis of the Bera-Jarque (1980) test for normality. Augmented Dickey-Fuller (1979) unit root tests and Kwiatkowski-Phillips-Schmidt-Shin (1992) tests for stationarity suggest that both $y_{t}$ and $\pi_{t}$ are $\mathrm{I}(0)$ series. $^{5}$

\footnotetext{
${ }^{5}$ The lag orders for the ADF tests reported in table 1 were chosen using the Schwarz (1978) information criterion. Under this criterion lag orders of 1 and 5 were deemed optimal for growth and inflation, respectively. The Akaike (1974) criterion selects higher orders of augmentation without qualitatively affecting the results of the tests.
}

However, a series of Ljung-Box tests for serial correlation suggests that there is a significant amount of serial dependence in the data.

Because one of our concerns in this paper is to estimate an extremely general specification of the variancecovariance structure, we present Engle's (1982) LM test for ARCH and Engle and Ng's (1993) test for differences in the response of volatility to the sign and size of shocks in table 1. Engle and Ng's approach facilitates a test of sign bias: whether positive and negative shocks to volatility affect future volatility differently. Size bias, where not only the sign, but also the magnitude of the innovation in volatility is important, can also be tested. Given the evidence of serial correlation in the raw data, the test for ARCH and the tests for sign and sign bias were performed on the residuals from a fourth-order autoregression, which was sufficient to ensure that the residuals were free from serial correlation. Choosing the order of the autoregression using either the Schwarz (1978) or the Akaike (1974) criteria does not qualitatively affect the evidence reported in table 1 .

The results in table 1 suggest that the data display strong evidence of conditional heteroskedasticity. Furthermore, it appears that the conditional volatility of real activity may be sensitive to the size and sign of the innovation. There is strong evidence of negative size bias, there is some evidence of positive size bias, and the joint test for both sign and size bias in variance is highly significant at all usual levels of confidence. Likewise, the tests suggest that the sign of innovations to inflation influences inflation volatility, with 
$\pi_{t}$ displaying positive size bias. The joint test is significant at all usual levels of confidence. ${ }^{6}$

Given the evidence in table 1 of conditional heteroskedasticity and sign and size bias in the data, we characterize the joint data-generating process underlying inflation and real activity as a multivariate asymmetric GARCH-in-mean model. The conditional mean equations of the model are specified as an augmented vector autoregressive moving average, VARMA $(p, q)$-M,

$$
Y_{t}=\mu+\sum_{i=1}^{p} \Gamma_{i} Y_{t-i}+\Psi \sqrt{h_{t}}+\sum_{j=1}^{q} \Theta_{j} \varepsilon_{t-j}+\varepsilon_{t}
$$

where $^{7}$

$$
\begin{gathered}
Y_{t}=\left[\begin{array}{c}
y_{t} \\
\pi_{t}
\end{array}\right], \quad \varepsilon_{t}=\left[\begin{array}{c}
\varepsilon_{y, t} \\
\varepsilon_{\pi, t}
\end{array}\right], \\
\sqrt{h_{t}}=\left[\begin{array}{c}
\sqrt{h_{y, t}} \\
\sqrt{h_{\pi, t}}
\end{array}\right], \quad \mu=\left[\begin{array}{l}
\mu_{y} \\
\mu_{\pi}
\end{array}\right], \\
\Gamma_{i}=\left[\begin{array}{ll}
\Gamma_{11}^{(i)} & \Gamma_{12}^{(i)} \\
\Gamma_{21}^{(i)} & \Gamma_{22}^{(i)}
\end{array}\right], \quad \Psi=\left[\begin{array}{ll}
\psi_{11} & \psi_{12} \\
\psi_{21} & \psi_{22}
\end{array}\right], \\
\Theta_{i}=\left[\begin{array}{ll}
\theta_{11}^{(i)} & \theta_{12}^{(i)} \\
\theta_{21}^{(i)} & \theta_{22}^{(i)}
\end{array}\right] .
\end{gathered}
$$

Under the assumption $\varepsilon_{t} \mid \Omega_{t} \sim N\left(0, H_{t}\right)$, the model may be estimated using maximum likelihood methods, subject to the requirement that $H_{t}$ be positive definite for all values of $\varepsilon_{t}$ in the sample. This assumption of symmetric response to shocks in the time-varying variance-covariance matrix must be considered tenuous, given the evidence in table 1 documenting the differing relative dynamic response of output and inflation volatility to positive and negative shocks of equal magnitude. To allow for the possibility of differing responses of this kind we extend the BEKK approach of Engle and Kroner (1995), using

$$
\begin{aligned}
H_{t}= & C_{0}^{* \prime} C_{0}^{*}+A_{11}^{* \prime} \varepsilon_{t-1} \varepsilon_{t-1}^{\prime} A_{11}^{*} \\
& +B_{11}^{* \prime} H_{t-1} B_{11}^{*}+D_{11}^{* \prime} \zeta_{t-1} \zeta_{t-1}^{\prime} D_{11}^{*},
\end{aligned}
$$

where

$$
\begin{gathered}
C_{0}^{*}=\left[\begin{array}{cc}
c_{11}^{*} & c_{12}^{*} \\
0 & c_{22}^{*}
\end{array}\right], \quad A_{11}^{*}=\left[\begin{array}{ll}
\alpha_{11}^{*} & \alpha_{12}^{*} \\
\alpha_{21}^{*} & \alpha_{22}^{*}
\end{array}\right], \\
B_{11}^{*}=\left[\begin{array}{ll}
\beta_{11}^{*} & \beta_{12}^{*} \\
\beta_{21}^{*} & \beta_{22}^{*}
\end{array}\right], \quad D_{11}^{*}=\left[\begin{array}{ll}
\delta_{11}^{*} & \delta_{12}^{*} \\
\delta_{21}^{*} & \delta_{22}^{*}
\end{array}\right]
\end{gathered}
$$

and

\footnotetext{
${ }^{6}$ In small samples the Engle-Ng (1993) size and sign bias tests may have low power. However, Brooks and Henry (2000) provide Monte Carlo evidence of the superior performance of these tests to that of the BDS test [Brock, Dechert, and Sheinkman (1987), revised in Brock et al. (1996)] in detecting asymmetric (i.e., sign-dependent) volatility. Brock, Hsieh, and LeBaron (1992) provide a full description of the BDS test.

${ }^{7}$ We choose the values of $p$ and $q$ that minimize the Schwarz information criterion. In the results below, $p=q=2$.
}

$$
\zeta_{t}=\left[\begin{array}{c}
\zeta_{y, t} \\
\zeta_{\pi, t}
\end{array}\right]=\left[\begin{array}{l}
\min \left\{\varepsilon_{y, t}, 0\right\} \\
\max \left\{\varepsilon_{\pi, t}, 0\right\}
\end{array}\right]
$$

Note that $\zeta_{y, t}$ allows for the observed negative sign and size bias in real activity, and $\zeta_{\pi, t}$ allows for the positive size bias in inflation. The inclusion of these variables allows for different relative responses to positive and negative shocks in the time-varying variance-covariance matrix, relaxing the assumption of symmetry in the BEKK model.

\section{Results and Specification Tests}

Table 2 reports quasi maximum likelihood (QML) parameter estimates, as well as specification and diagnostic tests, for the full model given by equations (3) and (4). Bollerslev and Wooldridge (1992) argue that, in the case of univariate GARCH models, asymptotically valid inference regarding normal QML estimates may be based upon robustified versions of the standard test statistics. The QML estimator for multivariate GARCH models was shown to be strongly consistent by Jeantheau (1998), and Comte and Lieberman (2003) proved the asymptotic normality of the estimator. ${ }^{8}$

These estimates confirm that the inflation-real-activity process is strongly conditionally heteroskedastic. The statistical significance of the off-diagonal elements of the matrices $A_{11}^{*}, B_{11}^{*}$, and $D_{11}^{*}$ also implies that innovations to inflation (real activity) significantly influence the conditional variance of real activity (inflation). The significance of the various elements of the matrix $D_{11}^{*}$ implies that the sign as well as the size of both inflation and activity innovations are important.

The evidence in table 2 suggests that the model is well specified. The standardized residuals, $z_{i t}=\varepsilon_{i t} / \sqrt{h_{i t}}$ for $i=$ $y, \pi$, and their corresponding squares satisfy the null of no fourth-order linear dependence of the $Q(4)$ and $Q^{2}(4)$ tests. Similarly, there is no evidence, at the 5\% level, of twelfthorder serial dependence in $z_{y, t}$ and $z_{y, t}^{2}$. On the basis of $Q^{2}(12)$, though, there is some evidence of twelfth-order dependence in the squared standardized residuals of inflation. For a well-specified model, $E\left(z_{i t}\right)=0$ and $E\left(z_{i t}^{2}\right)=1$. These conditions are not rejected at any standard level of significance. The model also significantly reduces the degree of skewness and kurtosis in the standardized residuals in comparison with the raw data. Similarly, the model predicts that $E\left(\varepsilon_{i, t}^{2}\right)=h_{i, t}$ for $i=y, \pi$ and $E\left(\varepsilon_{y, t} \varepsilon_{\pi, t}\right)=h_{y \pi, t}$. These conditions are not rejected at the $5 \%$ level.

Table 3 reports the results of applying robust conditional moment bias tests to the estimated model (Kroner \& Ng, 1998). These tests are based on a comparison of the crossproduct matrix of the residuals from the estimated model with the estimated covariance matrix. One indication that the estimated model provides a good characterization of the

\footnotetext{
${ }^{8}$ The model was also estimated assuming a conditional Student's $t$ distribution. The results were qualitatively unchanged. Details are available from the third author upon request.
} 
Table 2.-Multivariate Asymmetric GARCH-IN-Mean Model

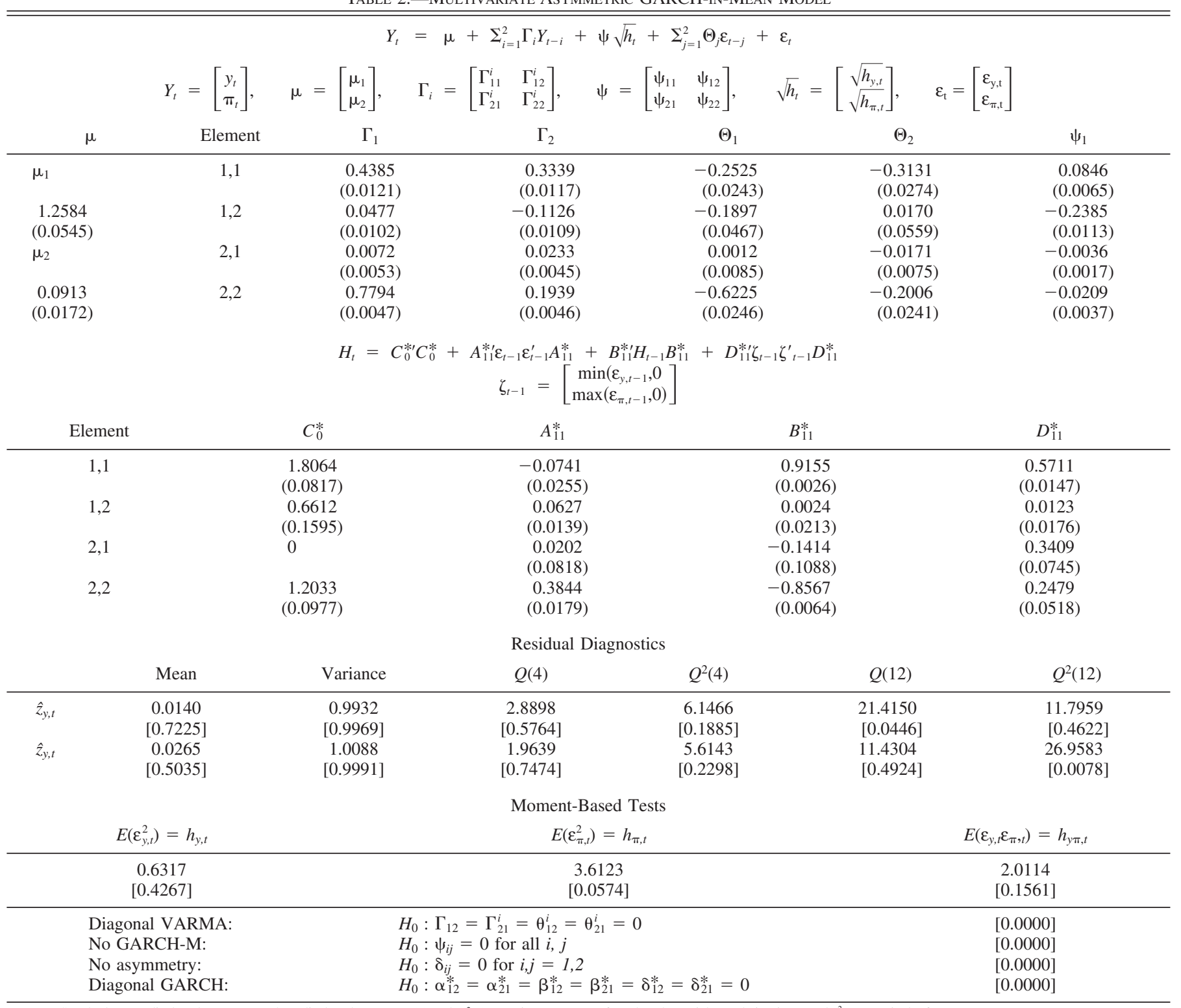

Notes: Standard errors displayed as $(\cdot) . P$-values displayed as $[\cdot] . Q(p)$ and $Q^{2}(p)$ are Ljung-Box tests for $p$ th-order serial correlation in $z_{j, t}$ and $z_{j, i}^{2}$, respectively, for $j=y$, $\pi$.

data is the absence of systematic patterns in the vertical distance between the elements of $\varepsilon_{y, t} \varepsilon_{\pi, t}$ and $h_{y \pi, t}$. This distance is measured by the generalized residual $u_{y \pi, t}=$ $\varepsilon_{y, t} \varepsilon_{\pi, t}-h_{y, \pi, t}$. A correctly specified model would imply $E_{t-1}$ $\left(u_{y \pi, t}\right)=0$; this means that $u_{y \pi, t}$ should be orthogonal to any variable known in period $t-1$. Similar generalized residuals $u_{i, t}=\varepsilon_{i, t} \varepsilon_{i, t}-h_{i, t}$ can be defined for $i=y, \pi$.

We check for three types of systematic biases in the generalized residuals. For sign bias, we define indicator variables $m_{1}^{i}=I\left(\varepsilon_{i, t-1}<0\right)$ for $i=y, \pi$, where $I(\cdot)=1$ if the argument is true. A test for quadrant bias can be based on a partition of $\varepsilon_{y, t-1} \varepsilon_{\pi, t-1}$ according to $\left(\varepsilon_{y, t-1}<0\right.$, $\left.\varepsilon_{\pi, t-1}<0\right),\left(\varepsilon_{y, t-1}>0, \varepsilon_{\pi, t-1}<0\right),\left(\varepsilon_{y, t-1}<0, \varepsilon_{\pi, t-1}>0\right)$, and $\left(\varepsilon_{y, t-1}>0, \varepsilon_{\pi, t-1}>0\right)$. The indicator variables $m_{2}^{i}$ relate to these respective quadrants. Finally, a set of indicators, $m_{3}^{i}$, can be defined that scale the sign bias indicators by the magnitude of the innovations. These variables can be used to detect sensitivity to the sign and size of the innovations.

Table 3 shows that, in the main, the model is well specified. Only two of the thirty generalized residual test statistics are significant at the $5 \%$ level. The indicator $m_{3}^{y, \pi}$, used to detect bias in the magnitude of $\varepsilon_{y, t-1}$ when $\varepsilon_{\pi, t}<0$, is significant for $u_{y, t}$. Similarly, for the conditional variance of inflation, only the indicator $m_{1}^{y}$ is significant, indicating some bias to forecasts of inflation volatility when growth innovations are negative. The conditional covariance equations display no evidence of quadrant or size and sign misspecification.

Finally, we note that all elements of the matrix $\Psi$ are statistically significant at the $5 \%$ level. This is consistent 
Table 3.-Robust Conditional Moment Tests

\begin{tabular}{|c|c|c|c|}
\hline Indicator & $u_{y, t}=\varepsilon_{y, t}^{2}-h_{y, t}$ & $\bar{u}_{y \pi, t}=\varepsilon_{y, t} \varepsilon_{\pi, t}-h_{y \pi, t}$ & $u_{\pi, t}=\varepsilon_{\pi, t}^{2}-h_{\pi, t}$ \\
\hline$m_{1}^{y}$ & $\begin{array}{c}0.2002 \\
{[0.6546]}\end{array}$ & $\begin{array}{c}1.1889 \\
{[0.2756]}\end{array}$ & $\begin{array}{c}6.0239 \\
{[0.0014]}\end{array}$ \\
\hline$m_{1}^{\pi}$ & 0.0007 & 0.5253 & 0.1048 \\
\hline & [0.9789] & [0.4686] & [0.7461] \\
\hline$m_{2}^{-,-}$ & $\begin{array}{l}4.4018 \\
{[0.03591}\end{array}$ & $\begin{array}{l}0.4363 \\
05089]\end{array}$ & $\begin{array}{l}0.2990 \\
0.5845]\end{array}$ \\
\hline$m_{2}^{-,+}$ & $\begin{array}{c}0.8892 \\
{[0.3457]}\end{array}$ & $\begin{array}{c}2.4581 \\
{[0.1169]}\end{array}$ & $\begin{array}{c}1.2379 \\
{[0.2659]}\end{array}$ \\
\hline$m_{2}^{+,-}$ & $\begin{array}{c}1.2342 \\
{[0.2666]}\end{array}$ & $\begin{array}{l}1.4946 \\
{[0.2215]}\end{array}$ & $\begin{array}{l}1.4946 \\
{[0.2215]}\end{array}$ \\
\hline$m_{2}^{+,+}$ & $\begin{array}{c}0.0004 \\
{[0.9844]}\end{array}$ & $\begin{array}{c}0.1814 \\
{[0.6701]}\end{array}$ & $\begin{array}{c}1.7098 \\
{[0.1910]}\end{array}$ \\
\hline$m_{3}^{v, y}$ & $\begin{array}{c}0.1471 \\
{[0.7014]}\end{array}$ & $\begin{array}{l}1.5014 \\
{[0.2204]}\end{array}$ & $\begin{array}{c}4.3499 \\
{[0.0370]}\end{array}$ \\
\hline$m_{3}^{\mathrm{y}, \pi}$ & $\begin{array}{c}0.1358 \\
{[0.7125]}\end{array}$ & $\begin{array}{l}0.1792 \\
{[0.67211}\end{array}$ & $\begin{array}{l}3.2139 \\
50.0730]\end{array}$ \\
\hline$m_{3}^{\pi, y}$ & $\begin{array}{c}0.8974 \\
0.3435]\end{array}$ & $\begin{array}{c}0.0001 \\
0.9941]\end{array}$ & $\begin{array}{c}0.5373 \\
{[0.4636]}\end{array}$ \\
\hline$m_{3}^{\pi, \pi}$ & $\begin{array}{c}0.7223 \\
{[0.3954]}\end{array}$ & $\begin{array}{c}0.6679 \\
{[0.4138]}\end{array}$ & $\begin{array}{c}1.0869 \\
{[0.2972]}\end{array}$ \\
\hline Sign Misspecification & \multicolumn{2}{|c|}{ Quadrant Misspecification } & Size and Sign Misspecification \\
\hline $\begin{array}{l}m_{1}^{y}=I\left(\varepsilon_{y, t-1}<0\right) \\
m_{1}^{\pi}=I\left(\varepsilon_{\pi, t-1}<0\right)\end{array}$ & \multicolumn{2}{|c|}{$\begin{array}{l}m_{2}^{-,-}=I\left(\varepsilon_{y, t-1}<0, \varepsilon_{\pi, t-1}<0\right) \\
m_{2}^{+,-}=I\left(\varepsilon_{y, t-1}>0, \varepsilon_{\pi, t-1}<0\right) \\
m_{2}^{-,+}=I\left(\varepsilon_{y, t-1}<0, \varepsilon_{\pi, t-1}>0\right) \\
m_{2}^{+,+}=I\left(\varepsilon_{y, t-1}>0, \varepsilon_{\pi, t-1}>0\right)\end{array}$} & $\begin{array}{l}m_{3}^{y, y}=\varepsilon_{y, t-1}^{2} I\left(\varepsilon_{y, t-1}<0\right) \\
m_{3}^{y, \pi}=\varepsilon_{y, t-1}^{2} I\left(\varepsilon_{\pi, t-1}<0\right) \\
m_{3}^{\pi, y}=\varepsilon_{\pi t-1}^{2} I\left(\varepsilon_{y, t-1}<0\right) \\
m_{3}^{\pi, \pi}=\varepsilon_{\pi t-1}^{2} I\left(\varepsilon_{\pi 2 t-1}<0\right)\end{array}$ \\
\hline
\end{tabular}

Notes: All tests are distributed as $\chi^{2}(1) . P$-values are displayed as $[\cdot]$. The misspecification indicator is defined so that $I(\cdot)$ takes the value 1 if the expression in the parentheses is satisfied and 0 otherwise.

with uncertainty about inflation and real activity affecting the respective conditional means. The implications of this are discussed further in a companion paper to the current research (Grier et al., 2004).

\section{Variance Impulse Response Functions}

In this section, we investigate the dynamics implied by the conditional variance-covariance structure of the model by perturbing the system with innovations to real activity and inflation. We refer to these innovations as news. Specifically, we trace the effects of news on the conditional variances (and covariance) through time, allowing for a different relative response to positive and negative news as implied by equation (4). Our analysis extends the generalized impulse response functions (GIRFs), introduced by Koop, Pesaran, and Potter (1996) in the context of multivariate nonlinear systems, to the conditional variances of a system (as opposed to the traditional analysis of the conditional means of series).

Since this technique is new in this context, we now provide more detail. Define the random vector $Q_{t}=$ vech $\left(H_{t}\right)$, where $H_{t}$ is, as defined in section III, the $2 \times 2$ conditional variance-covariance matrix of $\varepsilon_{t} ; Q_{t}$ will therefore be a $3 \times 1$ vector, whose first, second, and third elements are respectively given by $h_{y, t}, h_{y \pi, t}$, and $h_{\pi, t}$. The VIRF for a specific shock $v_{t}$ and history $\omega_{t-1}$ can then be given as

$$
\operatorname{VIRF}_{Q}\left(n, \boldsymbol{v}_{t}, \omega_{t-1}\right)=E\left[Q_{t+n} \mid \boldsymbol{v}_{t}, \omega_{t-1}\right]-E\left[Q_{t+n} \mid \omega_{t-1}\right]
$$

for $n=0,1,2, \ldots$ Hence, the VIRF is conditional on $v_{t}$ and $\omega_{t-1}$ and constructs the response by averaging out future innovations given the past and present. Given this, a natural reference point for the impulse response function is the conditional expectation of $Q_{t+n}$ given only the history $\omega_{t-1}$; in this benchmark response, the current innovation is also averaged out. Assuming that $v_{t}$ and $\omega_{t-1}$ are realizations of the random variables $V_{t}$ and $\Omega_{t-1}$, respectively, that generate realizations of $\{Q\}$, then [following the ideas proposed by Koop et al. (1996)] the VIRF defined in equation (5) can be considered to be a realization of a random variable given by

$$
\operatorname{VIRF}_{Q}\left(n, V_{t}, \Omega_{t-1}\right)=E\left[Q_{t+n} \mid V_{t}, \Omega_{t-1}\right]-E\left[Q_{t+n} \mid \Omega_{t-1}\right] .
$$

Note that the first and third elements of $\operatorname{VIRF}_{Q}\left(n, V_{t}, \Omega_{t-1}\right)$ give the impulse responses of the conditional variances of $y_{t}$ and $\pi_{t}$, respectively, and the second element represents the impulse response relating to the conditional covariance. ${ }^{9}$

It is important to distinguish between shocks and news. We reserve the term shocks for the contemporaneously correlated vector of disturbances $\varepsilon_{t}$; we treat news as a vector of i.i.d. innovations. These innovations, $v_{t}$, may be referred to as the underlying innovations or, alternatively, as independent news, obtained via a Jordan decomposition of the conditional variance-covariance matrix $H_{t}$. If $\lambda_{t s}, s=$ 1,2 , denote the eigenvalues of $H_{t}$ with corresponding eigenvectors $\tilde{\zeta}_{t s}, s=1,2$, then the symmetric matrix $H_{t}^{1 / 2}$ is

\footnotetext{
${ }^{9}$ Hafner and Herwartz (2001) also consider such an extension and derive analytical expressions for the VIRFs of multivariate GARCH models.
} 
defined as $H_{t}^{1 / 2}=\Xi_{t} \Lambda_{t}^{1 / 2} \Xi_{t}^{\prime}$, with $\Xi_{t}=\left(\tilde{\zeta}_{t 1}, \tilde{\zeta}_{t 2}\right)$ and $\Lambda_{t}=$ $\operatorname{diag}\left(\lambda_{t 1}, \lambda_{t 2}\right)$. Therefore, $\hat{v}_{t}$ is drawn from the vector of standardized residuals $\hat{z}_{t}$. This atheoretic approach ensures identification and uniqueness if, as found in this analysis, the elements of $\hat{z}_{t}$ are not normally distributed. ${ }^{10}$

Analogous to GIRFs, a number of alternative conditional versions of the VIRFs can be defined. ${ }^{11}$ Given the nature of the conditional variance-covariance structure capturing potential sign and size bias effects, of particular interest is an evaluation of the significance of the differing relative or asymmetric effects of positive and negative activity and inflation innovations of $h_{y, t}, h_{y \pi, t}$ and $h_{\pi, t}$. For instance, the response functions can be used to measure the extent to which negative impulses may (or may not) be more persistent than positive impulses. Furthermore, we may assess the potential diversity in the dynamic effects of positive and negative impulses to the conditional volatilities of output growth and inflation, and to their conditional covariance.

Let $\operatorname{VIRF}_{Q}\left(n, V_{t}^{+}, \Omega_{t-1}\right)$ denote the VIRF from conditioning on the set of all possible positive innovations, where $V_{t}^{+}=\left\{v_{t} \mid v_{t}>0\right\}$, and let $\operatorname{VIRF}_{Q}\left(n,-V_{t}^{+}, \Omega_{t-1}\right)$ denote the VIRF from conditioning on the set of all possible negative impulses. The distribution of the random asymmetry measure,

$$
\begin{aligned}
A S Y_{Q}\left(n, V_{t}^{+}, \Omega_{t-1}\right)= & \operatorname{VIRF}_{Q}\left(n, V_{t}^{+}, \Omega_{t-1}\right) \\
& -\operatorname{VIRF}_{Q}\left(n,-V_{t}^{+}, \Omega_{t-1}\right),
\end{aligned}
$$

will be centered on 0 if positive and negative shocks have exactly the same effect. The distribution of equation (7) can provide an indication of the asymmetric effects of positive and negative innovations.

The asymmetry measure we propose is analogous to the measure proposed by van Dijk, Franses, and Boswijk (2000) for the case of GIRFs. However, a notable distinction is that the measure in equation (7) is composed of the difference between the variance response functions, $\operatorname{VIRF}_{Q}\left(n, V_{t}^{+}\right.$, $\left.\Omega_{t-1}\right)$ and $\operatorname{VIRF}_{Q}\left(n,-V_{t}^{+}, \Omega_{t-1}\right)$, in contrast to the sum of the corresponding generalized impulse response versions. This distinction arises because VIRFs are made up of the squares of the innovations (and therefore will be of the same sign), in contrast to the case of GIRFs, where positive and negative impulses cause the response functions to take opposite signs. Note that the conditional variancecovariance structure proposed in this paper allows for the potential diversity in the relative response to positive and negative shocks to enter through the terms $\zeta_{y, t}=\min$

\footnotetext{
10 This approach to the definition of news can also be found in Hafner and Herwartz (2001). Note that our approach differs from that of Gallant, Rossi, and Tauchen (1993), who directly set $\hat{v}_{t}=\hat{\varepsilon}_{t}$; however, in that case the shocks would be contemporaneously correlated and so would fail our definition of news.

${ }^{11}$ For instance, it is possible to condition on a particular shock and treat the variables generating the history as random, or to condition on a particular history and allow the shocks to be the random variables. Alternatively, particular subsets of shocks/histories could be conditioned upon [see Koop et al. (1996) for further details].
}

$\left\{\varepsilon_{y, t}, 0\right\}$ and $\zeta_{\pi, t}=\max \left\{\varepsilon_{\pi, t}, 0\right\}$, in the form of $\zeta_{t-1} \zeta_{t-1}^{\prime}$ in equation (4), where $\zeta_{t}=\left(\zeta_{y, t}, \zeta_{\pi, t}\right)^{\prime}$. Hence, if the matrix of coefficients, $D_{11}^{*}$, defined in equation (4) is not significantly different from 0 then the VIRF will not distinguish between positive and negative innovations. If, on the other hand, $D_{11}^{*}$ is significant, then the possibility of differing relative responses to positive and negative impulses arises, even though $\operatorname{VIRF}_{Q}\left(n, V_{t}^{+}, \Omega_{t-1}\right)$ and $V I R F_{Q}\left(n,-V_{t}^{+}, \Omega_{t-1}\right)$ will be of the same sign.

A second distinction between the VIRFs and GIRFs following naturally from this discussion is that, unlike GIRFs, the property of linearity in the impulse no longer holds for VIRFs. Therefore, an innovation of $\kappa v_{t}$, where $\kappa$ is a scalar, will not have $\kappa$ times the effect of $v_{t}$, if we consider conditional volatility responses.

Finally-akin to GIRFs, and importantly-these VIRFs allow for composition dependence in multivariate models ${ }^{12}$ and avoid problems of dependence on the size and sign of the news (that is, the underlying innovations). However, in contrast to GIRFs, VIRFs exhibit dependence on the history through the conditional variance-covariance matrix at time 0 when the innovation occurs [that is, through $Q_{0}=$ $\left.\operatorname{vech}\left(H_{0}\right)\right]$. This is clear from equation (4) on setting $t=1$.

Without assuming that the standardized innovations are symmetrically distributed, it is not possible to construct analytical expressions for the conditional expectations for the nonlinear structure proposed in this paper. Therefore, Monte Carlo methods of stochastic simulation need to be used. ${ }^{13}$ The algorithm essentially follows that described in Koop et al. (1996), but allows for time-varying composition dependence. In more detail, using the 637 histories in the observed sample, in order to allow for the observed timevarying dependence among the elements of the estimated residuals $\hat{\varepsilon}_{t}$, these are first transformed to obtain $\hat{z}_{t}=$ $\hat{\varepsilon}_{t} \hat{\mathrm{H}}_{t}^{-1 / 2}$, using the Jordan decomposition. Next, the joint distribution of the underlying innovations (news), at each history, is drawn randomly and independently (with replacement) to produce 100 realizations of the innovations at each history. These innovations are identically and independently distributed over time. Recovering the time-varying contemporaneous dependence, 63,700 realizations of the impulse responses $\operatorname{VIRF}_{Q}\left(n, v_{t}, \omega_{t-1}\right)$ are therefore computed for horizons $n=0,1, \ldots, N$, with $N=50$. Finally, $R=500$ replications are used to average out the effects of the impulses. A number of alternative response functions are considered and described in what follows.

\footnotetext{
12 Despite the independence of the underlying innovations, the response functions recover the contemporaneous dependence at each point in time through knowledge of the estimated time-varying conditional variancecovariance matrix. Hence, a shock to the conditional volatility of output growth, for example, is not isolated from having a contemporaneous effect on the conditional variance of inflation and vice versa. See Lee and Pesaran (1993) and Pesaran and Shin (1998), who consider composition dependence in (multivariate) conditional mean equations

13 See Granger and Teräsvirta (1993, chapter 8), Koop et al. (1996), and Pesaran and Shin (1998) for a background to the methods employed here.
} 
FigURE 1.-VIRF FOR A GROWTH IMPULSE ON $h_{y, t}, h_{\pi, t}$ AND $h_{y \pi, t}$

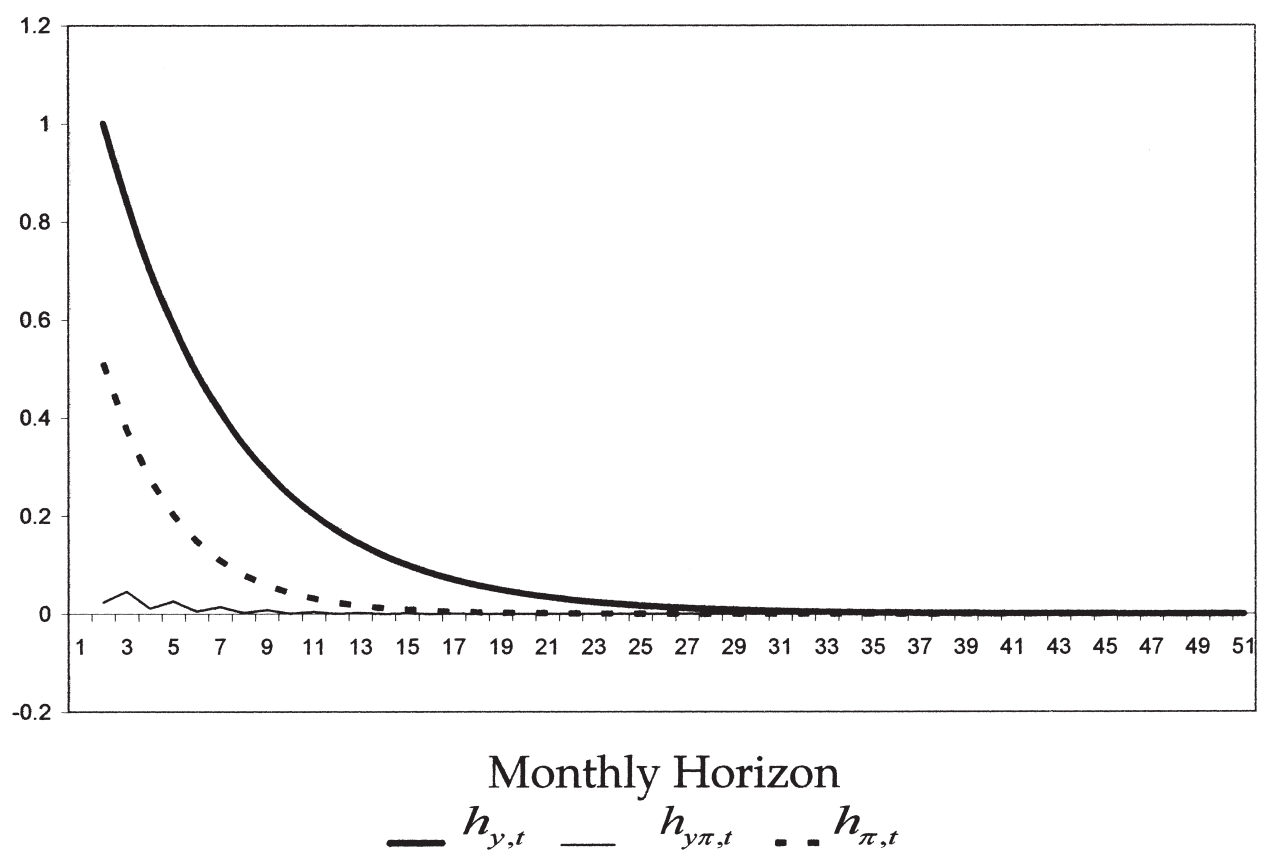

Note: The figure displays the VIRFs for (i) the conditional variance of activity, $h_{y, t}$ (dark solid line), (ii) the conditional variance of inflation, $h_{\pi, t}$ (dashed line), and (iii) the conditional covariance $h_{y \pi, t}$ (thin solid line), to news about output growth only that causes $h_{y, t}$ to rise by a unit on impact.

Figures 1 and 2 display the VIRFs for news about real activity and inflation bootstrapped from the data. Figure 1 displays the response functions for the conditional variances of activity and inflation and the conditional covariance to news about output growth only that causes $h_{y, t}$ to rise by a unit on impact. News concerning the growth of industrial production results in a markedly higher and more persistent response from $h_{y, t}$ than from $h_{\pi, t}$. The peak response of $h_{y, t}$ is approximately twice the maximum response of $h_{\pi, t}$ to the same impulse. Further, for activity volatility, the effects of the impulse die out after roughly 2 years, whereas the effect of the growth impulse on inflation volatility dissipates after roughly 1 year.

FiguRe 2.-VIRF FOR AN INFLATION IMPULSE ON $h_{y, t}, h_{\pi, t}$, AND $h_{y \pi, t}$

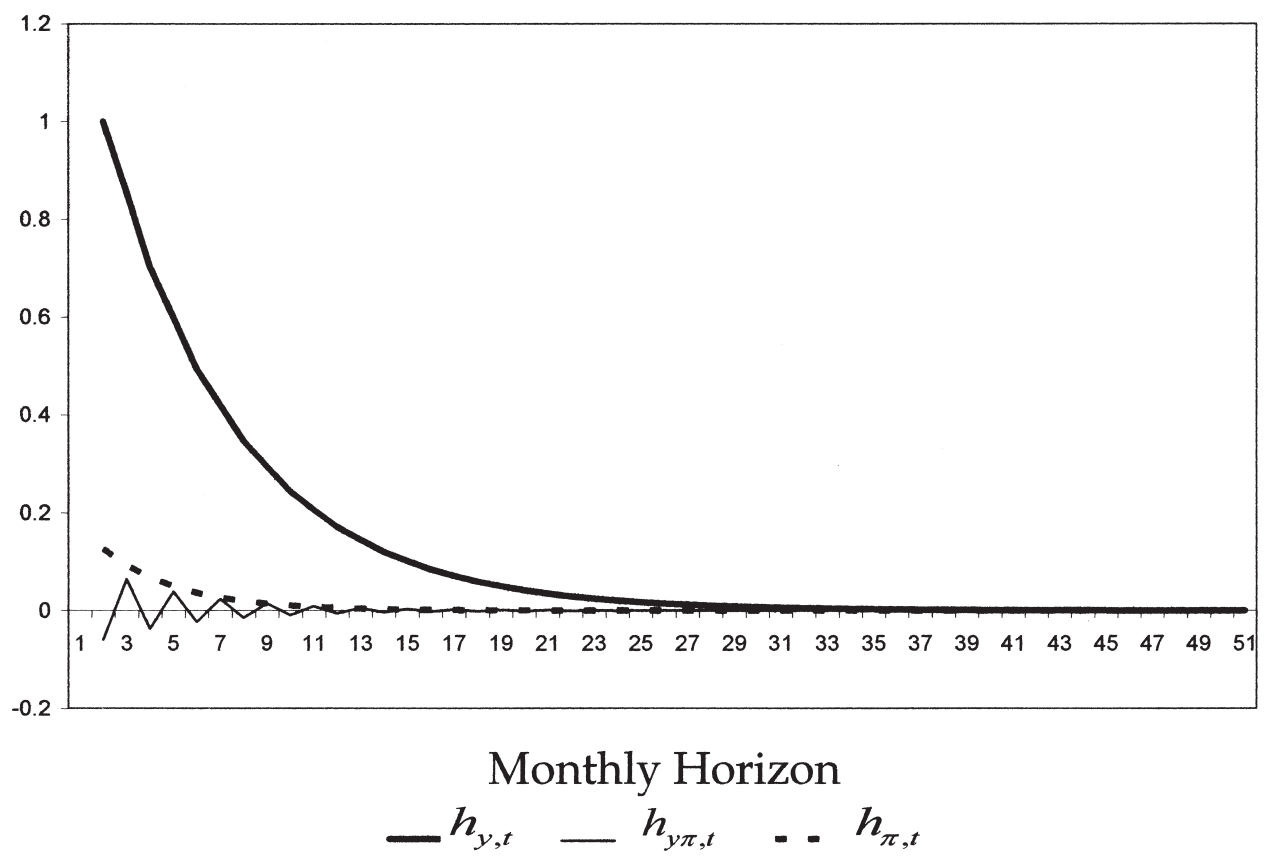

Note: The figure displays the VIRFs for (i) the conditional variance of activity, $h_{y, t}$ (dark solid line), (ii) the conditional variance of inflation, $h_{\pi, t}$ (dashed line), and (iii) the conditional covariance $h_{y \pi, t}($ thin solid line), to news about inflation only that causes $h_{y, t}$ to rise by a unit on impact. 
The response of $h_{y, t}, h_{\pi, t}$, and the conditional covariance to news about inflation only that causes $h_{y, t}$ to rise by one unit on impact is displayed in figure 2 . Here, the peak response of $h_{\pi, t}$ is roughly one-fifth that of $h_{y, t}$. The response of growth volatility again dissipates after approximately 2 years, whereas the inflation volatility response dies away relatively quickly, after approximately 7 months.

The response functions displayed in figures 1 and 2 for the conditional covariance to the respective activity and inflation impulses oscillate either close to or around the zero axis and are unlikely to be economically significant.

Computation of the asymmetry measures for an activity (inflation) impulse to the conditional variance and covariance of the activity and inflation series highlights the pernicious effects of bad news about activity. A negative growth innovation results in more persistent growth volatility $($ statistic $=-0.4432, t$-ratio $=-49.0194)$, more persistence in covariance (statistic $=-0.2895, t$-ratio $=$ -50.9665 ) and more persistence in inflation volatility (statistic $=-0.1845, t$-ratio $=-59.8990)$ than an unexpected positive activity shock of equal magnitude. Contractionary activity innovations lead to higher and more persistent uncertainty about inflation and activity.

Good news about inflation, that is, an unexpected innovation that results in a decrease in the inflation rate, has a greater long-run impact on growth volatility (statistic = $-0.0250, t$-ratio $=-11.4620$ ), covariance (statistic $=$ $-0.1437, t$-ratio $=-12.6692$ ), and inflation volatility (statistic $=-2.6225, t$-ratio $=-10.5997)$ than an unanticipated increase in inflation of equal magnitude.

In contrast to bad news about growth, unexpected inflation actually leads to less, rather than more, persistence in growth volatility. This may be suggestive of the stabilizing effects of monetary policy in response to an increase in inflation and inflation uncertainty. However, in general these asymmetry measures are small in magnitude relative to the size of the initial news and are therefore perhaps unlikely to be of great economic significance. The possible exception is the measure of asymmetry in the response of inflation volatility to inflationary news. This measure is sufficiently large to have economic as well as statistical significance.

\section{Conclusions}

As detailed in the introduction to this paper, uncertainty has a central role in a wide variety of macroeconomic models. There also now exists a growing empirical literature that investigates the effects of uncertainty on realizations of macroeconomic variables. The results in our paper contribute to this analysis of macroeconomic uncertainty in three ways.

First, they highlight the potential specification error in studies of uncertainty that impose second-moment restrictions that are not supported by the data. In particular, we find that GARCH models of inflation and real activity will be misspecified unless asymmetries and uncertainty spillovers are incorporated into the empirical specification. Failure to do so must raise concerns about any inferences made on the basis of these models.

Second, using VIRFs, we find considerable persistence in the response of uncertainty to macroeconomic shocks. For example, it can take up to 3 years before the uncertainty generated by a shock to economic activity dissipates. This persistence in uncertainty, which to our knowledge has not been documented elsewhere, suggests that the effects of shocks that generate uncertainty may persist for periods far longer than have previously been realized. The macroeconomic effects of uncertainty, as hypothesized by researchers such as Friedman (1977) and Black (1987) inter alia and identified empirically in papers such as those by Grier and Perry (2000), Henry and Olekalns (2002), and Grier et al. (2004), inter alia, may therefore have a relatively longlasting influence on macroeconomic outcomes.

Finally, our variance impulse response analysis demonstrates that macroeconomic uncertainty responds asymmetrically to macroeconomic shocks. The impact of bad news (that is, positive shocks to inflation and negative shocks to growth) on the variances of growth and inflation and on their covariance differs in magnitude and persistence from that of good news of similar magnitude. In particular, inflation uncertainty displays an asymmetric response to inflationary shocks that is both statistically significant and economically meaningful.

\section{REFERENCES}

Akaike, Hirotsugu, "A New Look at Statistical Model Identification," IEEE Transactions an Automatic Control AC-19 (1974), 716-723.

Bera, Anil K., and Carlos M. Jarque, "Efficient Tests for Normality, Heteroscedasticity, and Serial Independence of Regressions," Economics Letters, 6 (1980), 255-259.

Black, Fisher, Business Cycles and Equilibrium (New York: Basil Blackwell, 1987).

Bollerslev, Tim, and Jeffery M. Wooldridge, "Quasi-Maximum Likelihood Estimation and Inference in Models with Time Varying Covariances," Econometric Reviews, 11 (1992), 143-172.

Brock, William A., W. Davis Dechert, and Jose A. Sheinkman, "A Test of Independence Based on the Correlation Dimension," Department of Economics, University of Wisconsin, Madison, SSRI no. 8702 (1987).

Brock, William A., W. Davis Dechert, Jose A. Sheinkman, and Blake LeBaron, "A Test of Independence Based on the Correlation Dimension," Econometric Reviews 15: (1996), 197-235.

Brock, William A., David A. Hsieh, and Blake LeBaron, Nonlinear Dynamics, Chaos, and Instability: Statistical Theory and Economic Evidence (Cambridge, MA: The MIT Press, 1992).

Brooks, Chris, and Ólan T. Henry, "Can Portmanteau Non-linearity Tests Serve As General Misspecification Tests? Evidence from symmetric and asymmetric GARCH models," Economics Letters 67 (2000), 245-251.

Caporale, Tony, and Barbara McKiernan, "The Relationship between Output Volatility and Growth; Evidence from Postwar UK Data," Scottish Journal of Political Economy 43:2 (1996), 229-236.

Comte, Fabienne, and Offer Lieberman, "Asymptotic Theory for Multivariate GARCH Processes," Journal of Multivariate Analysis 84 (2003), 61-84.

Cukierman, Alex, and Paul Wachtel, "Differential Inflationary Expectations and the Variability of the Rate of Inflation: Theory and 
Evidence," American Economic Review 69 (September 1979), 595-609.

Cukierman, Alex and Allan H. Meltzer, "A Theory of Ambiguity, Credibility, and Inflation under Discretion and Asymmetric Information," Econometrica 54 (1986), 409-421.

Dickey, David, and Wayne A. Fuller, "Likelihood Ratio Statistics for Autoregressive Time Series with a Unit Root" Econometrica 49 (1979), 1057-1072.

Engle, Robert F, "Autoregressive Conditional Heteroskedasticity with Estimates of the Variance of United Kingdom Inflation," Econometrica 50 (1982), 987-1007.

, "Estimates of the Variance of U.S. Inflation Based on the ARCH Model," Journal of Money, Banking and Credit 15 (August 1983), 169-184.

Engle, Robert F., and Kenneth F. Kroner, "Multivariate Simultaneous Generalized ARCH," Econometric Theory 11 (1995), 122-150.

Engle, Robert F., and Victor K. Ng, "Measuring and Testing the Impact of News on Volatility," Journal of Finance 48 (1993), 1749-1778.

Friedman, Milton, "Nobel Lecture: Inflation and Unemployment," Journal of Political Economy 85 (June 1977), 451-472.

Gallant, A. Ronald, Peter E. Rossi, and George Tauchen, "Nonlinear Dynamic Structures," Econometrica 61 (1993), 871-907.

Granger, Clive, and Timo Teräsvirta, Modelling Nonlinear Dynamic Relationships (Oxford University Press, 1993).

Grier, Kevin, and Mark Perry, "The Effects of Uncertainty on Macroeconomic Performance: Bivariate GARCH Evidence," Journal of Applied Econometrics, 15 (2000), 45-58.

Grier, Kevin, and Gordon Tullock, "An Empirical Analysis of CrossNational Economic Growth, 1951-1980," Journal of Monetary Economics 24 (1989), 259-276.

Grier, Kevin, Ólan T. Henry, Nilss Olekalns, and Kalvinder Shields, “The Asymmetric Effects of Uncertainty on Inflation and Output Growth," Journal of Applied Econometrics 19:5 (2004), 551-565.

Hafner, Christian M., and Helmut Herwartz, "Volatility Impulse Response Functions for Multivariate GARCH Models," CORE discussion paper 2001/3 (2001).

Hayford, Mark D., "Inflation Uncertainty, Unemployment Uncertainty and Economic Activity," Journal of Macroeconomics 22:2 (2000), 315-329.

Henry, Ólan T., and Nilss Olekalns, "The Effect of Recessions on the Relationship between Output Variability and Growth," Southern Economic Journal 68 (2002), 683-692.

Holland, A. Steven, "Comment on "Inflation Regimes and the Sources of Inflation Uncertainty," Journal of Money, Credit and Banking 25:3 (1993), 514-520.
Huizinga, John, "Inflation Uncertainty, Relative Price Uncertainty, and Investment in U.S. Manufacturing," Journal of Money, Credit and Banking 25:3 (1993), 521-549.

Jansen, Dennis, "Does Inflation Uncertainty Affect Output Growth? Further Evidence," Federal Reserve Bank of St. Louis Review (July/ August 1989), 43-54.

Jeantheau, Thierry, "Strong Consistency of Estimators for Multivariate GARCH Models," Econometric Theory 14 (1998), 70-86.

Koop, Gary, M. Hashem Pesaran, and Simon M. Potter, "Impulse Response Analysis in Nonlinear Multivariate Models," Journal of Econometrics 74 (1996), 119-147.

Kormendi, Roger C., and Phillip G. Meguire, "Macroeconomic Determinants of Growth: Cross-Country Evidence," Journal of Monetary Economics, 16 (1985), 141-163.

Kroner, Kenneth F., and Victor K. Ng, "Modeling Asymmetric Comovements of Asset Returns," The Review of Financial Studies 11:4 (1998), 817-844.

Kwiatowski, Denis, Peter C. B. Phillips, Peter Schmidt, and Yongcheol Shin, "Testing the Null Hypothesis of Stationarity against the Alternative of a Unit Root: How Sure Are We That Economic Time Series Have a Unit Root?" Journal of Econometrics 54 (1992), $159-178$.

Lee, Kevin C., and M. Hashem Pesaran, "Persistence Profiles and Business Cycle Fluctuations in a Disaggregated Model of UK Output Growth," Richerche Economiche 47 (1993), 293-322.

Logue, Dennis, and Thomas D. Willett, "A Note on the Relation between the Rate and Variability of Inflation," Economica 43 (May 1976), 151-158.

Okun, Arthur, "The Mirage of Steady Inflation," Brookings Papers on Economic Activity (1971), 485-498.

Pesaran, M. Hashem, and Yongcheol Shin, "Generalised Impulse Response Analysis in Linear Multivariate Models," Economics Letters 58 (1998), 17-29.

Ramey, Garey, and Valerie Ramey, "Cross-Country Evidence on the Link between Volatility and Growth," American Economic Review 85 (1995), 1138-1151

Schwarz, Gideon, "Estimating the Dimension of a Model," The Annals of Statistics 6 (1978), 461-464.

Taylor, John B., "On the Relationship between the Variability of Inflation and Average Inflation Rates," Carnegie-Rochester Conference Series in Public Policy (1981), 57-85.

van Dijk, Dick, Phillip H. Franses, and Hans P. Boswijk, "Asymmetric and Common Absorption of Shocks in Nonlinear Autoregressive Models," Econometric Institute Research Report no. 2000-01/A (2000).

Woodford, Michael, "Learning to Believe in Sunspots," Econometrica 58 (1990), 277-307. 